ISBN 978-93-84422-76-9

International Conference on Research \& Innovation in Environment, Civil and Architecture Engineering

(RIECAE-17)

Bangkok (Thailand), Feb. 6-7, 2017

\title{
Load Transfer Test of Post-Tensioned Anchorage Zones in High Strength Concrete
}

\author{
Jee-Sang Kim, and Byeong Hun Woo \\ Seokyeong University, Civil and Architectural Engineering Department Republic of Korea \\ e-mail: zskim@skuniv.ac.kr / qudgns160@gmail.com
}

\begin{abstract}
The post-tensioning methods use a large amounts of strands to introduce a prestressing force into concrete. When the strands are strained, a considerable load is imposed on the concrete in the anchorage zone. Therefore, the cross section becomes larger and more reinforcements are used to prevent cracking. To decrease the inefficiency such as the increase of cross section and the use of a large amount of reinforcements, various studies are under way. In this study, the behaviors were evaluated by load transfer test of a post tensioned anchorage zones using high strength concrete. A total of 8 specimens were prepared for various amounts of spiral reinforcement and the reinforcing degree of lateral reinforcements. Compared those specified with the Korean Highway Bridge Design Code, the spiral reinforcement was found to be removable, but stronger lateral reinforcing is required rather than those specified in the design code. It may be possible to simplify lateral reinforcements when using spiral reinforcement.
\end{abstract}

Keywords: Post-tension, Lateral reinforcement, Spiral, Reinforcements, Crack.

\section{Introduction}

In the post tension method, a considerable load is imposed on the concrete due to a large amounts of strands tensioning, so that the cross section of anchorage zone becomes larger and more reinforcements are used more than necessary to prevent usual cracks. The dimensions of anchorage zone increase and the materials used also increase, resulting in environmentally and economically ineffective results. To reduce such inefficiency, high strength or high performance concrete were applied, which is being actively researched recently, or pretension method and post-tension method are applied at the same time. A research on UHPC post-tensioned anchorage zone [1] revealed that the reduction of reinforcement may be possible. In the case of using a single unbounded strand in post tensioned anchorage zones the additional reinforcement is unnecessary. Another research on experiment and finite element analysis of the post tensioned anchorage zones using Ultra-High Performance Concrete under active research in Korea [2]. It showed that sufficient strength and performance were obtained without reinforcing.

In this study, the performance of the post-tensioned anchorage zones using 100MPa high strength concrete was examined by the load transfer test and crack pattern, crack width, the stresses reinforcements were measured.

\section{Specimens}

The characteristics of the test specimens used in this experiment were designed according the exist specifications [3], [4]. Following the regulations of ETAG013, the sections must satisfy the conditions shown in (1), (2) and TABLE I, and the result is summarized in TALBE II and Fig. 1

$$
\begin{aligned}
& A_{C}=x \bullet y=a \bullet b \\
& x \geq 0.85 a, y \leq 1.15 b
\end{aligned}
$$


TABLE I: Requirements for Specimens

\begin{tabular}{|c|c|}
\hline & Requirements \\
\hline $\begin{array}{c}\text { Vertical } \\
\text { Reinforcement }\end{array}$ & $A_{s} \leq 0.003 A_{c}$ \\
\hline Specimen Height & $\begin{array}{c}\text { More than two times the long dimension of } \\
\text { section side dimension }\end{array}$ \\
\hline
\end{tabular}

TABLE II: Specimen Dimensions

\begin{tabular}{|c|c|}
\hline & Dimension $(\mathbf{m m})$ \\
\hline Width & 340 \\
\hline Length & 340 \\
\hline Height & 850 \\
\hline
\end{tabular}

Where, $A_{c}$ is the cross-section area of the concrete $\left(\mathrm{mm}^{2}\right)$, a is width or length $(\mathrm{mm}), \mathrm{b}$ is length or width $(\mathrm{mm})$, and $A_{s}$ is the total area of the vertical reinforcements $\left(\mathrm{mm}^{2}\right)$. To meet the requirements for vertical reinforcements and area of ETAG013, four D10 reinforcements were used for vertical reinforcement and the dimensions were determined as those specified in TABLE I, which are given by the restriction in the experimental site and equipment's capacity.

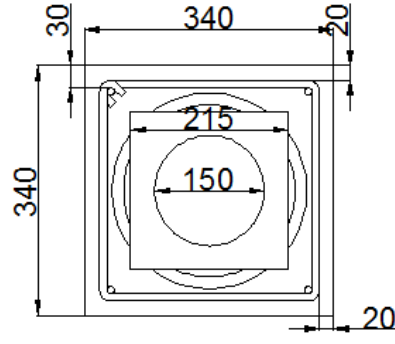

(a) Section dimension

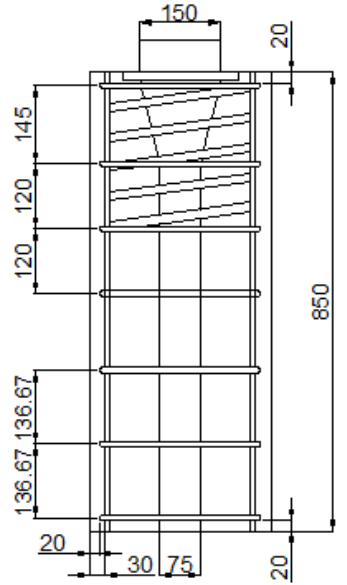

(b) Side surface dimension

Fig. 1 Specimen dimension

Following the specifications of ETAG013, there is requirement that the lateral reinforcements should not exceed $50 \mathrm{Kg}$ per $1 \mathrm{~m} 3$ of concrete volume, and they should be evenly distributed along the specimen's height. Although the condition of not exceeding $50 \mathrm{Kg}$ was followed, the spacings of reinforcements is arranged to meet the requirements of [4]. This condition is summarized in TABLE III and Fig. 2 [3], [5]. In Fig. 2, the names given to the specimens were classified to US by using spiral reinforcement and NS by non-using spiral reinforcement respectively, and numbered as the number of tensile resistance reinforcements except for three lateral reinforcements to prevent fracture failure at the bottom.

TABLE III: Lateral Reinforcements Design Condition For 2010 Korea Highway Bridge Design Code [4]

\begin{tabular}{|c|c|}
\hline Case & Condition \\
\hline Condition 1 & $\begin{array}{l}\text { Reinforcements have to settle close to the surface of member, and extend in the entire width, as long as } \\
\text { cover thickness allows }\end{array}$ \\
\hline Condition 2 & $\begin{array}{l}\text { Reinforcements should be distributed in accordance section with the distance of } 2.5 \mathrm{~d}_{\text {burst }} \text {, but not exceeding } \\
1.5 \text { times the corresponding lateral dimension of the section, and distributed in front of loading surface along } \\
\text { the both axis, and the bursting reinforcements centre should coincide with the } \mathrm{d}_{\text {burst }} \text {. }\end{array}$ \\
\hline Condition 3 & The reinforcements spacing should not exceed 24 times the diameter of rebar or 300mm. \\
\hline
\end{tabular}

Where, $d_{\text {burst }}$ is the location of the maximum bursting force specified in the 2010 Korea Highway Bridge Design Code [4], as shown in (3). 


$$
d_{\text {burst }}=0.5(h-2 e)+5 \sin \alpha
$$

Where, $\mathrm{h}$ is the width or length dimension of the side of specimen $(\mathrm{mm})$, e is the eccentric distance between the centre of the anchorage equipment and the centre of specimen $(\mathrm{mm})$, and $\alpha$ is the angle between anchorage and specimen during loading(degree). The lateral reinforcements are D10, and the spiral reinforcements are D16. To meet the condition 3 of TABLE III, the spacing of lateral reinforcements was $240 \mathrm{~mm}$ at maximum, so it was adjusted according to the number of lateral reinforcements and dimensions of reinforcing area. The anchorage equipment is VSL TYPE EC 5-12 from VSL Korea Co. [6]. The load base of specimen was 7 twisted twelve $12.7 \mathrm{~mm}$ strand of SWPC-7B $1860 \mathrm{MPa}$, with $\mathrm{F}_{\mathrm{pk}}=2073.53 \mathrm{KN}$, where, $\mathrm{F}_{\mathrm{pk}}$ is characteristic ultimate resisting force of tensile elements of tendon. The thickness of concrete cover between lateral reinforcements was 20mm [4], [7], [8], [9].

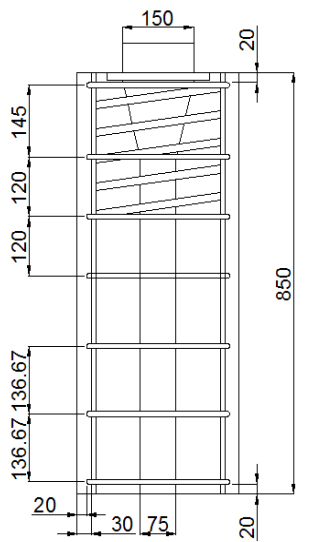

(a) US-4

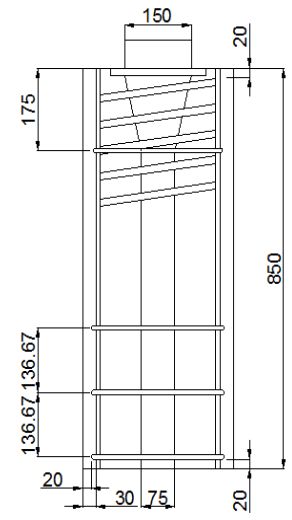

(d) US-1

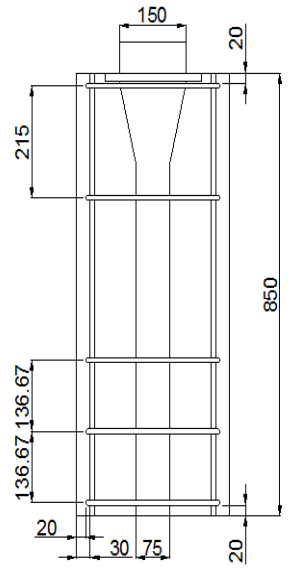

(g) NS-2

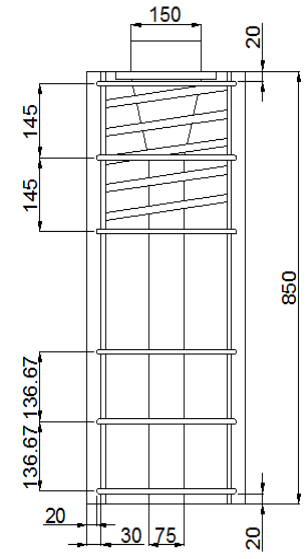

(b) US-3

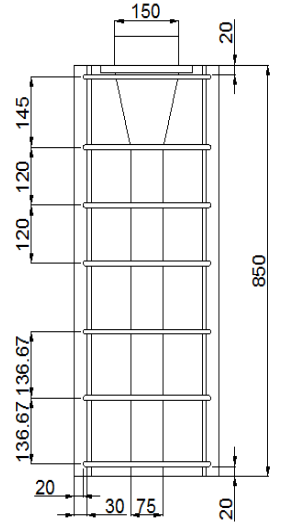

(e) NS-4

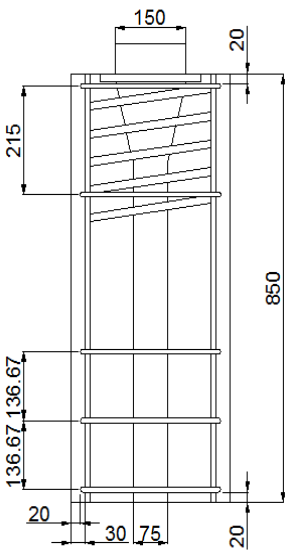

(c) US-2

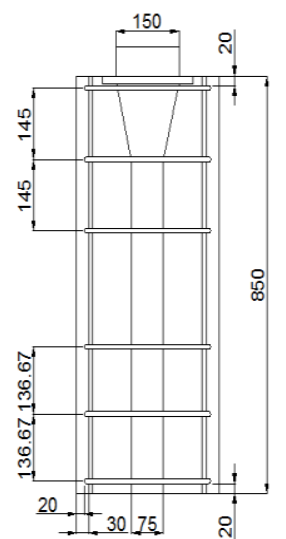

(f) NS-3

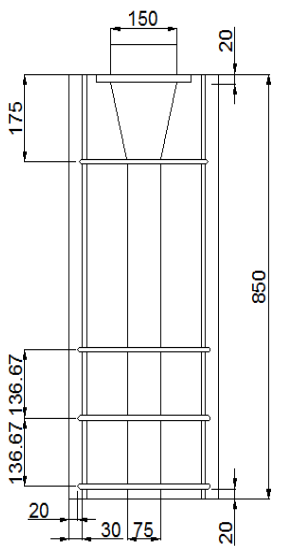

(h) NS-1

Fig. 2 Specimen details 
The specimens were fabricated using 100MPa high strength concrete. They were de-molded after one day air curing and steam-cured for 3days. Concrete characteristics such as compressive strength, split strength, flexural tensile strengths are summarized in TABLE IV.

TABLE IV: Characteristic of Concrete

\begin{tabular}{|c|c|}
\hline Characteristics & Value \\
\hline Compressive Strength $(\mathrm{MPa})$ & 105.1 \\
\hline Splitting Strength $(\mathrm{MPa})$ & 4.84 \\
\hline Flexural Strength $(\mathrm{MPa})$ & 7.01 \\
\hline
\end{tabular}

\section{Measurement and Loadings}

In this study, cracks and reinforcements stress were measured and analyzed. For the crack measurement, four PI gauges were installed on the left and right sides of the specimens and the reinforcements strain gauges were installed on the left and right sides of the spiral reinforcement and lateral reinforcements as shown in Fig. 3 (b).

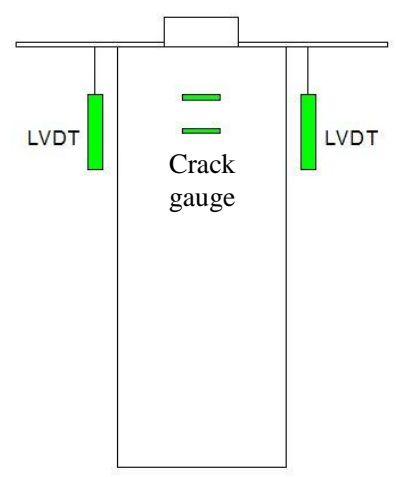

(a) Crack gauge plan

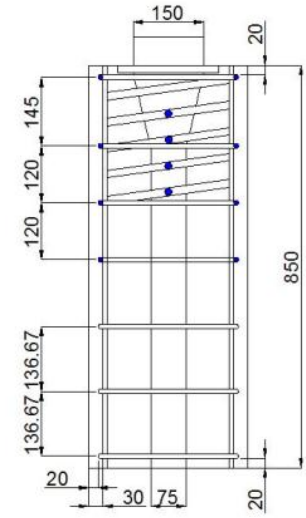

(b) Reinforcements plan

Fig. 3 Crack and reinforcements measurement plan

The $3000 \mathrm{KN}$ capacity UTM was used and loaded to $2551 \mathrm{KN}$ to meet the $1.1 \mathrm{Fpk}$ specified in ETAG013 and considered UTM's capacity. The judgement criteria of specimen failure were based on the yield strength of lateral reinforcements. Load plan and operation procedures were followed by the experimental method of ETAG013, and the application conditions are shown in TABLE V and Fig. 4. If all the condition of TALBE V are satisfied, the strain stabilization is conducted as shown in Fig. 3 [2], [5].

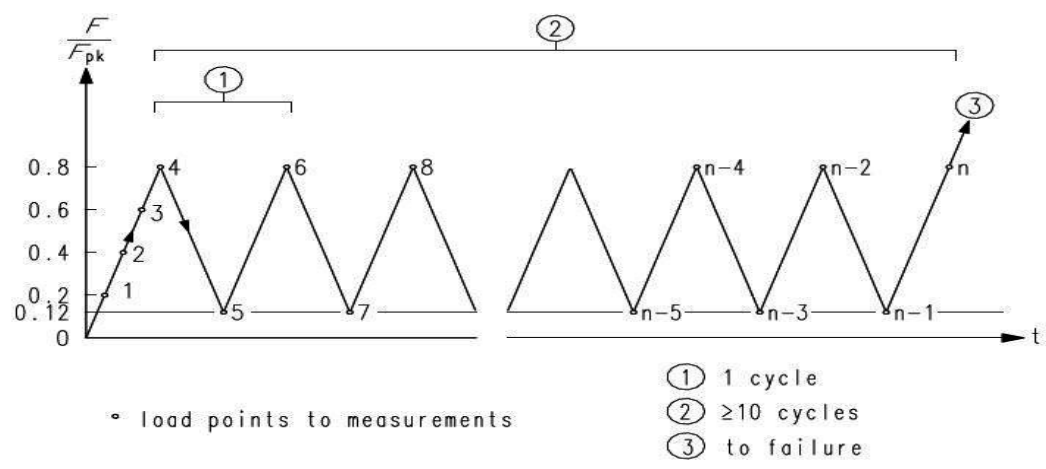

Fig. 4 Strain stabilizing cycle 
TABLE V: Conditions to the Strain Stabilizing

\begin{tabular}{|c|c|c|}
\hline & Loads & Limitations \\
\hline 1 & $\begin{array}{c}\text { First load: } \\
\text { Up to } 80 \% \text { of strand's nominal tensile } \\
\text { strength }\end{array}$ & Crack width $\leq 0.1 \mathrm{~mm}$ \\
\hline 2 & $\begin{array}{l}\text { Repeat at least } 10 \text { cycle loading up to } \\
12 \sim 80 \% \text { of strand's nominal tensile } \\
\text { strength }\end{array}$ & $\begin{array}{cc} & \text { Step } 2 \\
- & \text { Strain increase } \leq 0.5 \% \\
- & \text { Crack width } \leq 0.02 \mathrm{~mm} \\
& \text { Final Step } \\
& -\quad 0.12 \mathrm{~F}_{\mathrm{pk}} \text { Crack } \leq 0.1 \mathrm{~mm} \\
& -\quad 0.8 \mathrm{~F}_{\mathrm{pk}} \text { Crack } \leq 0.25 \mathrm{~mm} \\
-\quad & \text { Specimen surface must be stabilized } \\
\end{array}$ \\
\hline 3 & $\begin{array}{l}\text { Gradually loading when the specimen } \\
\text { failure }\end{array}$ & $\mathrm{F}_{\mathrm{u}} \geq 1.1 \mathrm{~F}_{\mathrm{pk}}$ \\
\hline
\end{tabular}

\section{Experimental Result and Discussion}

All specimens satisfied the strain stabilization conditions except for NS-1 and NS-2. The loading proceeded to the maximum load after the strain stabilization except for NS-1 and NS-2. All of NS specimens didn't satisfy $1.1 \mathrm{~F}_{\mathrm{pk}}$, but NS-3 and NS-4 finished the experiment at near $1.0 \mathrm{~F}_{\mathrm{pk}}$. The relations between load and crack width from experiment results are shown in Fig. 5.

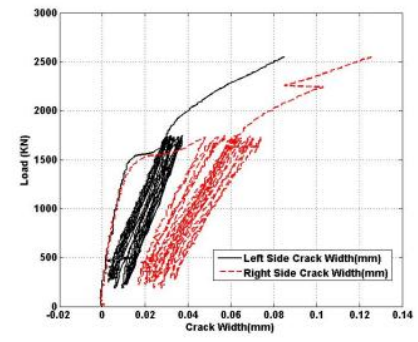

(a) US-4

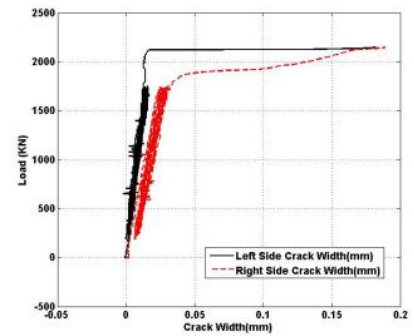

(e) NS-4

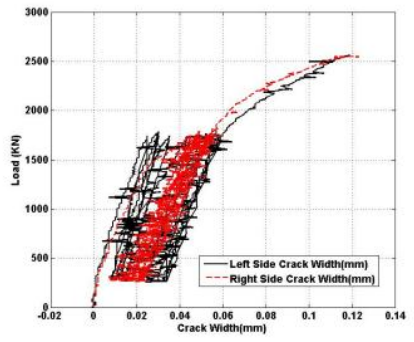

(b) US-3

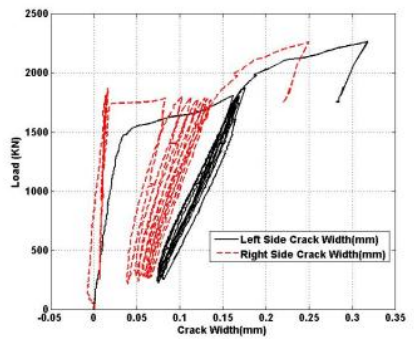

(f) NS-3

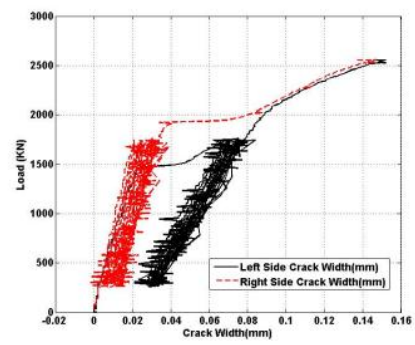

(c) US-2

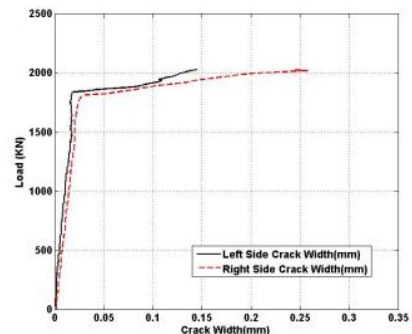

(g) NS-2

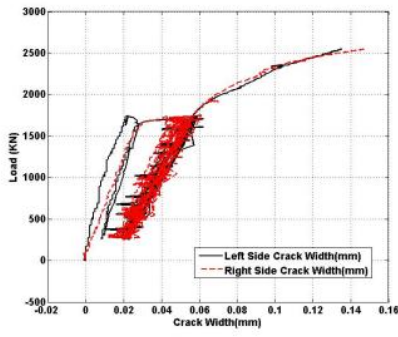

(d) US-1

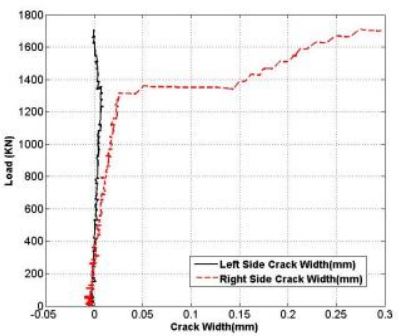

(h) NS-1

Fig. 5 Load-crack width relations

All the NS specimens showed the first cracks at initial loading, and US-2, US-3 specimen underwent initial cracking after the strain stabilization step, while the US-1 specimen underwent initial cracking at the second stage of the strain stabilization. The initial crack of US-4 specimen generated at the fifth stage of the strain stabilization. The cracking pattern of NS and US specimens is shown in Fig. 6 [6].

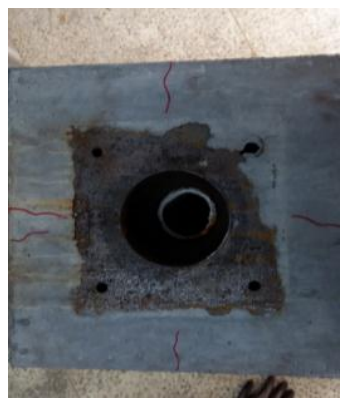

(a) Top crack pattern

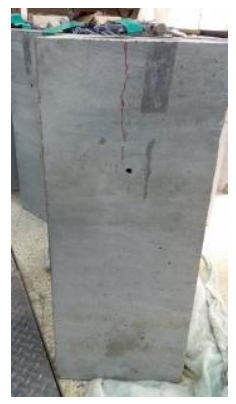

(b) Side crack pattern

Fig. 6 Experiment result of specimen crack pattern 
Cracks due to spalling force and bursting force were observed at the top of specimens, and at the all surfaces of specimens. After the first cracking, it was found to extend upward and downward.

In the case of lateral reinforcements, all NS specimens yielded at the final load point, but the US specimens did not yield either the spiral reinforcement and lateral reinforcements at the final load $2551 \mathrm{KN}$. The results of the reinforcements are shown in Fig. 7, and the results of the load and the reinforcements stress are shown in TABLE VI.

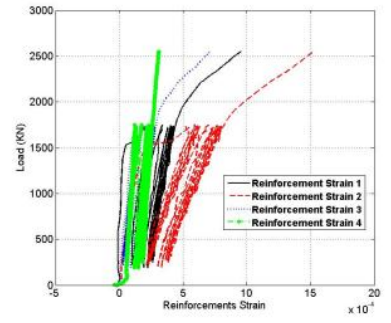

(a) US-4

Lateral reinforcements

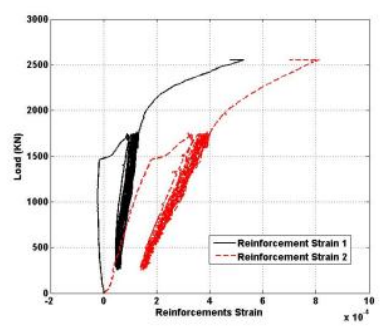

(e) US-2

Lateral reinforcements

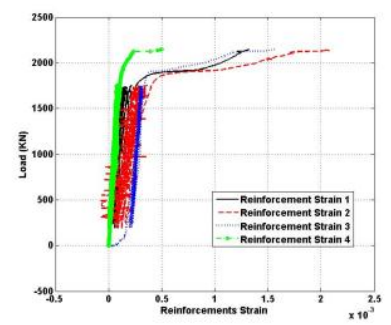

(i) NS-4

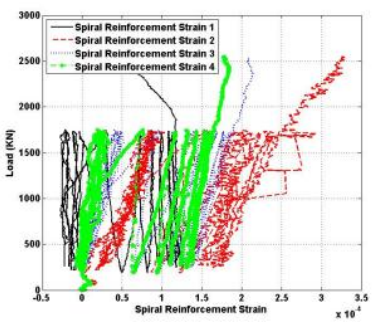

(b) US-4 Spiral

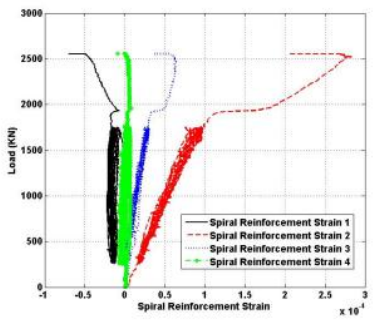

(f) US-2 Spiral

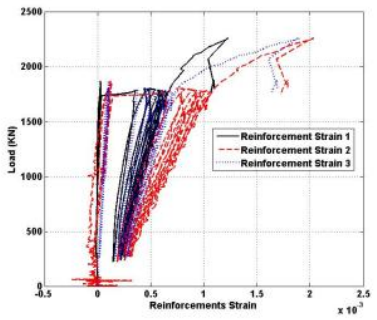

(j) NS-3

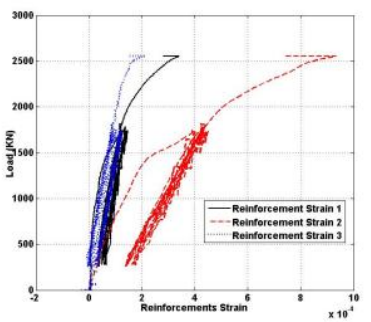

(c) US-3

Lateral reinforcements

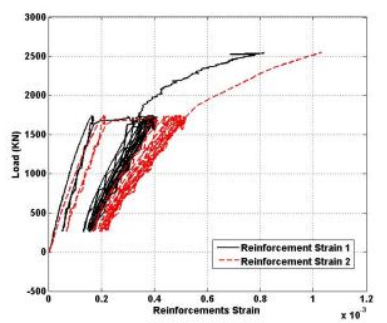

(g) US-1

Lateral reinforcements

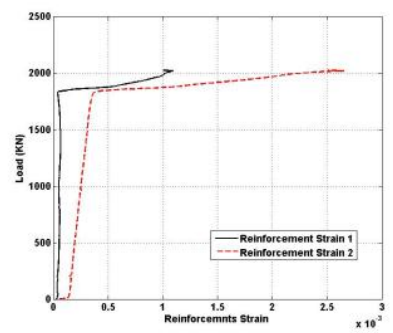

(k) NS-2

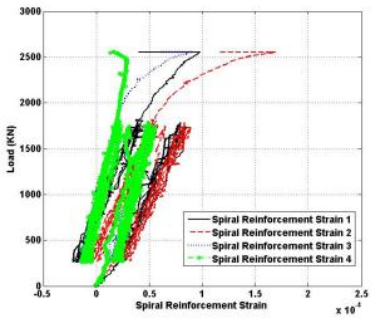

(d) US-3 Spiral

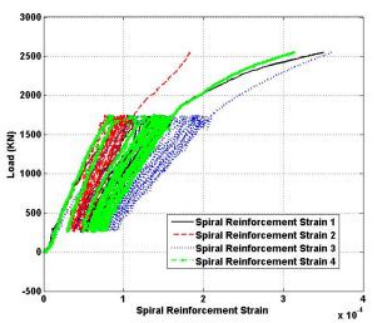

(h) US-1 Spiral

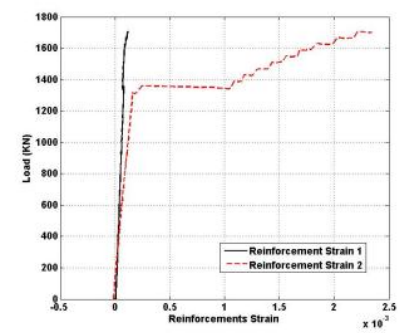

(1) NS-1

Fig. 7 Load-reinforcements stress relations

The NS specimen's reinforcements yielded, but the US specimen's reinforcements did not yield as shown in the load-reinforcements stress relationship in fig. 7. However, the US-4 of the US specimens showed the largest stress in the lateral reinforcements. The reason for this is that the lateral reinforcements of US-1 and US-4 burdened more than the other specimens due to cracks in the gauge attachment area.

TABLE VI: Reinforcements Stresses and Loads

\begin{tabular}{|c|c|c|}
\hline Specimen & Final Load(KN) & Stresses(MPa) \\
\hline US-4 & 2556 & $\begin{array}{c}\text { Lateral reinforcements: } 306, \\
\text { Spiral: 65.8 }\end{array}$ \\
\hline US-3 & 2556 & $\begin{array}{c}\text { Lateral reinforcements: } 186.8, \\
\text { Spiral: } 33.8\end{array}$ \\
\hline US-2 & 2556 & $\begin{array}{c}\text { Lateral reinforcements: } 162.2, \\
\text { Spiral: } 56.6\end{array}$ \\
\hline US-1 & 2551.4 & $\begin{array}{c}\text { Lateral reinforcements: } 206, \\
\text { Spiral: } 72\end{array}$ \\
\hline NS-4 & 2147.2 & 400 (Yielded) \\
\hline NS-3 & 2266.3 & 400 (Yielded) \\
\hline NS-2 & 2029 & 400 (Yielded) \\
\hline NS-1 & 1708 & 400 (Yielded) \\
\hline
\end{tabular}


From the experimental results, it is expected that the US specimen can be loaded greater than $1.23 \mathrm{~F}_{\mathrm{pk}}$, which may suggest the simplification of lateral reinforcements. NS specimens showed that NS-1 and NS-2 resisted higher than expected and NS-3 and NS-4 met the strain stabilization conditions of ETAG013, it might can be the basis of removal of spiral reinforcement, but reinforcing should be stronger than those given in [4].

\section{Verification of highway bridge design code}

In this study, the crack widths and reinforcements stress for various load steps are compared with those specified in Korea Highway Bridge Design Code. TABLE VII is the limitation of the cracks and reinforcements stress specified in [4].

TABLE VII: Load, Crack and Reinforcements Limit [4]

\begin{tabular}{|c|c|c|}
\hline Case & \multicolumn{2}{|c|}{ Limit Condition } \\
\hline $\begin{array}{c}\text { Crack } \\
\text { (PS Strand) }\end{array}$ & Dry Condition & Max. $\left(0.2 \mathrm{~mm}\right.$ or $\left.0.005 \mathrm{t}_{\mathrm{c}}\right)$ \\
\cline { 2 - 3 } $\begin{array}{c}\text { Reinforcements } \\
\text { Stress }\end{array}$ & \multicolumn{2}{|c|}{ Met Condition $\left(0.6 \mathrm{f}_{\mathrm{y}}\right.$ or $\left.250 \mathrm{MPa}\right)$ at $0.35 \mathrm{P}_{\mathrm{pu}}$} \\
\hline Load & \multicolumn{2}{|c|}{ Min. $\left(0.8 \mathrm{f}_{\mathrm{pu}}\right.$ or $\left.0.9 \mathrm{f}_{\mathrm{py}}\right)$} \\
\hline
\end{tabular}

Where, $t_{c}$ is the minimum cover thickness between outer concrete surface and reinforcements surface of the outermost, and $\mathrm{f}_{\mathrm{y}}$ is the yield stress of reinforcements. The yield stress of reinforcements applied to this experiment is $400 \mathrm{MPa}$ and the limiting stress of reinforcements proposed in [4] is $240 \mathrm{MPa}$. $\mathrm{P}_{\mathrm{pu}}$ is the maximum load considering the number of strands used and is the same value as $F_{p k} . F_{p u}$ is the tensile strength of the tendon( $\mathrm{MPa})$, and $\mathrm{f}_{\mathrm{py}}$ is the yield stress of tendon(MPa).

To meet the specified criteria in TABLE VII, the crack width must be $0.2 \mathrm{~mm}$ when the cover thickness of lateral reinforcements was applied $20 \mathrm{~mm}$. The reinforcements stress limit is $240 \mathrm{MPa}$ and load limit is $0.9 \mathrm{f}_{\mathrm{py}}$, each comparative graph is shown in Fig. 8.

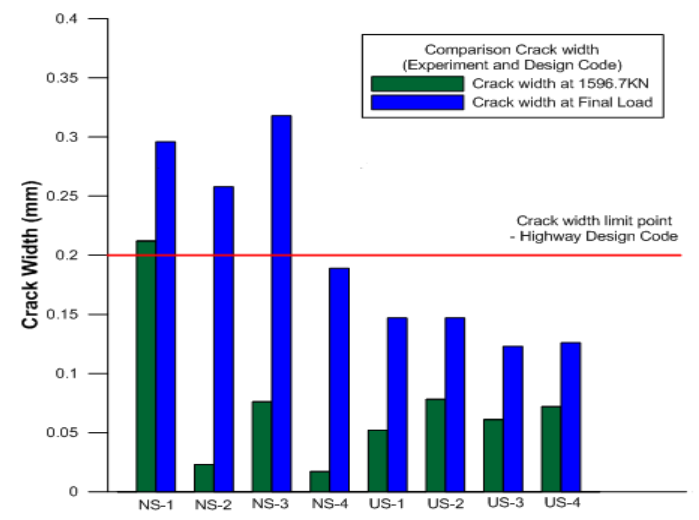

(a) Crack widths

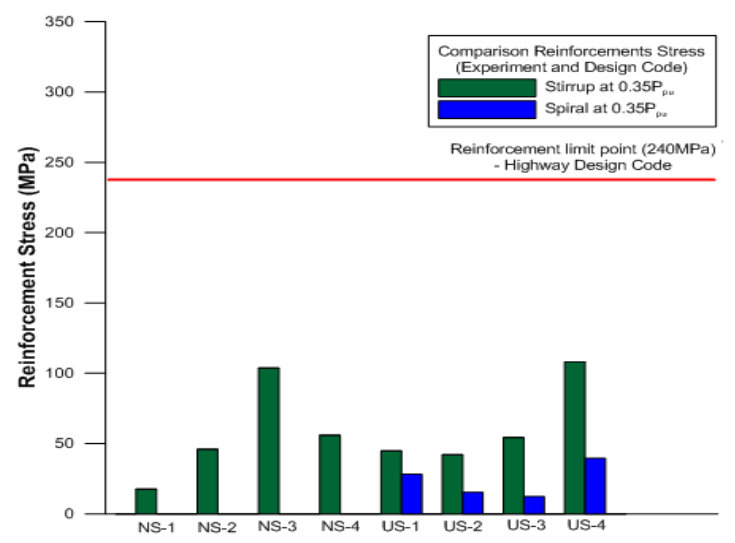

(b) Reinforcement stresses 


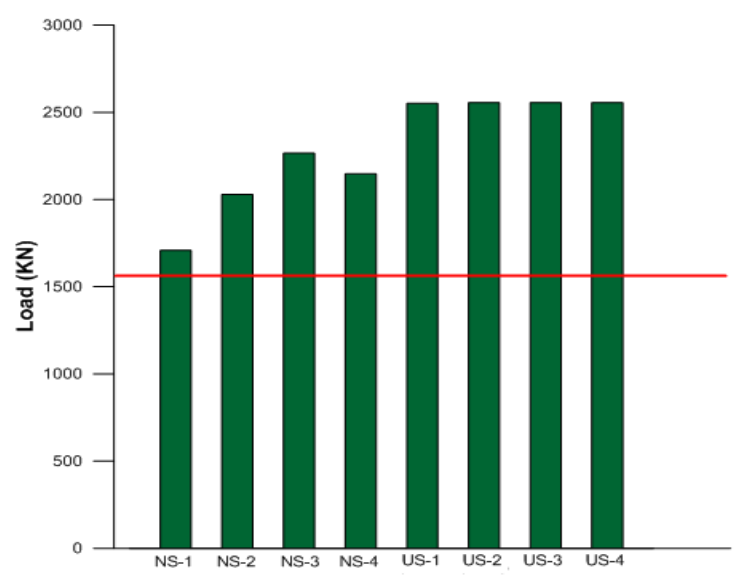

(c) Loads

Fig. 8 Comparison experiment results and design code

In the comparison of the crack widths, the crack width tends to be considerably less than $0.2 \mathrm{~mm}$ at the load point $0.9 f_{p y}$ except for the NS-1 specimen. At the final loads, the measured crack widths of each specimen were less than $0.2 \mathrm{~mm}$ except NS-1, NS-2 and NS-3 specimens. Also, in the case of the reinforcements stress, a considerable margin was left at $0.35 \mathrm{P}_{\mathrm{pu}}$, and the load is higher than the 2010 Korea Highway Bridge Design Code's load limitation. From the results, it can be concluded that post-tensioned anchorage zones using $100 \mathrm{MPa}$ high strength concrete is significantly underestimated when design code is applied. Therefore, it is necessary to apply the new design criteria for the post-tensioned anchorage zones using high strength concrete.

\section{Conclusions}

In this study, the behaviors of post-tensioned anchorage zones using $100 \mathrm{MPa}$ high strength concrete was examined through the evaluation of crack widths and reinforcements stress, and compared with 2010 Korea Highway Bridge Design Code.

- In the NS-3 specimen, it was possible to remove the spiral reinforcement, but a somewhat stronger reinforcing was required than those gien by the Korean Design Code. And it was confirmed that the lateral reinforcements reinfocing can be simplified through the US specimens.

- The load test results of all specimens had a considerable margin to those specified in the Code. Especially, NS-1 specimen showed that more than $0.9 \mathrm{f}_{\mathrm{py}}$ load limit, so it is necessary to make a new test procedure for post-tensioned anchorage zones using high strength concrete.

The crack widths and reinforcements stresses from this experiments show a considerable difference to those in current Code. It is suggested that the criteria for reinforcements stress, reinforcements spacing design and crack widths of the post-tensioned anchorage zones using high strength concrete should be newly regulated.

\section{References}

[1] Choi, Yoon Seok, Experimental Evaluation and Finite Element Analysis of Post-Tensioned Anchorage Zones Using UHPC, 2013, Master's Thesis, Seokyeong University (in Korean)

[2] Ah Sir Cho, Yeong Wook Jo, Byoung Kap Jeon, Thomas H.-K. Kang, Development and Performance Test for Unbonded Post-Tensioned Anchor, Journal of the Korea Concrete Institute, Vol. 27, No.1, 2015, pp.102-142 (in Korean)

[3] EOTA, ETAG013, 2002, Chapter B, pp. 79-87

[4] Ministry of Land, Transport and Maritime Affairs, Highway Bridge Bridge Design Code, 2010, Chapter 4, Concrete Bridge, pp. 133-146 (in Korean)

[5] Jee-Sang Kim, Changbin Joh, Yoon-Seok Choi, Load Transfer Test of Post-Tensioned Anchorage Zone in Ultra High Performance Concrete, Scientific Research Publishing, Engineering, 2015, 7, pp. 115-128

[6] VSL Korea, Post-Tensioning Systems, pp. 7 
[7] AMERICAN ASSOCIATION OF STATE HIGHWAY BRIDGE AND TRANSPORTATION OFFICIALS (AASHTO), AASHTO-LRFD, 2012, Chapter 5, pp. 122-144

[8] American Concrete Institute, Analysis and Design of Reinforced Concrete Bridge Structures (ACI 343R-95), 1995, Chapter 5, pp. 102-109

[9] American Concrete Institute, Building Code Requirements for Structural Concrete (ACI 318-11) An ACI Standard and Commentary, 2011, Chapter 18, pp. 302-306 